\title{
Do Parenting and Family Characteristics Moderate the Relation between Peer Victimization and Antisocial Behavior? A 5-year Longitudinal Study
}

\author{
Grace S. Yang and Vonnie C. McLoyd, University of Michigan
}

\begin{abstract}
Past research has demonstrated that relationships with peers and parents play salient roles in various child outcomes. However, little research has examined the confluence of these two factors in the context of peer victimization. In particular, little is known about which family and parental factors mitigate or intensify the impact of adverse peer relations. The current study bridged this gap by testing whether maternal support and family conflict moderated the association between peer victimization and antisocial behavior. Moderation effects were found for girls but not boys. Cross-lagged path analyses of nationally representative longitudinal data $(N=1046$; 53 percent boys; Time 1: $\left.\mathrm{M}_{\text {age }}=10.7\right)$ showed that, among girls, higher levels of maternal warmth and mother-child communication significantly attenuated the link between early peer victimization and later antisocial outcomes. By contrast, greater family conflict significantly increased antisocial outcomes among girls who experienced peer victimization. For boys, early peer victimization significantly predicted antisocial outcomes, regardless of parenting and family factors. All findings remained significant even after controlling for preexisting antisocial tendencies and demographic factors, as well as for the stability of victimization in the model.
\end{abstract}

Keywords: peer victimization; antisocial behavior; maternal warmth; parent-child communication; family conflict

\section{Introduction}

Children who bully others have normative beliefs that are more accepting of aggressive and antisocial behavior (Anderson \& Huesmann, 2003; Huesmann \& Kirwil, 2007). Unfortunately, children who are bullied also increasingly develop normative beliefs that are more tolerant of aggressive and antisocial behavior. Frequent victimization may encourage children to value violent behavior as a legitimate and effective mechanism for defending themselves against peers, leading to greater aggressive outcomes in the future. Research has shown that experiencing aggression as a victim in school, the neighborhood, or the home predicts increases in later aggression through changes in Michigan, B267 East Hall, 530 Church Street, Ann Arbor, MI 48109, USA. Email: gyang@umich.edu 
normative beliefs (Orue et al., 2011), and that children who suffer interpersonal rejection and aggression are vulnerable to dysfunctional social-cognitive biases, increasing their propensity for antisocial outcomes (Crick \& Dodge, 1994). These findings are consistent with social cognitive theory, which posits that children learn social behaviors not only through direct experiences, but also by observing the behaviors of others and the outcomes of those behaviors (Bandura, 1986, 2002).

Scholars have suggested that we can advance our understanding of the consequences of witnessing and experiencing peer bullying by investigating the interactive influences of various contextual elements, including family processes (Hong \& Espelage, 2012; Lynch \& Cicchetti, 2002). These suggestions draw heavily on Bronfenbrenner's (1986) social-ecological model, which posits that understanding development requires the study of the ecological system in which growth occurs, taking account of influences at multiple levels of proximity to the child. Relatively little empirical research has explored these contextual influences in relation to negative peer experiences and their impact on children's development. The present study uses longitudinal data to extend knowledge in this area by examining the extent to which the quality of mother-child relations and the family environment moderates the association between children's early peer victimization and prospective development of antisocial behavior. It directs attention to influences that operate at the 'mesosystem' level of Bronfenbrenner's ecological model, a term used to denote the principal settings in which children spend their time - two of which are the family setting and the peer setting.

\section{The Interplay between Peer Victimization and Antisocial Behavioral Problems}

The findings of a handful of studies suggest that peer victimization functions as an antecedent of externalizing problems like aggression, impulsivity, and antisocial behavior (Hanish \& Guerra, 2002; Ostrov, 2010; Schwartz, McFadyen-Ketchum, Dodge, Pettit, \& Bates, 1998). However, other research shows the reverse pathway. For example, Hodges, Boivin, Vitaro, and Bukowski (1999) found evidence that externalizing problems preceded victimization rather than victimization leading to the development of externalizing problems. Theorists hypothesized that externalizing problem behaviors may repel peers and increase the likelihood that children with these problems will become alienated and targets of bullying (e.g., Dodge, Lochman, Harnish, Bates, \& Pettit, 1997; Morrow, Hubbard, Rubin, \& McAuliffe, 2008; Salmivalli \& Helteenvuori, 2007).

Instead of taking a unidirectional approach - in which victimization comes either before or after externalizing behaviors - some scholars argue that the connection between victimization and externalizing problems among children should be understood within a framework of mutual processes involving continuous interplay between various externalizing symptoms and peer victimization. In keeping with this view, Reijntjes et al.'s (2011) meta-analysis of 14 longitudinal studies revealed that externalizing problems, including antisocial behavior, are both antecedents and consequences of peer victimization. Accordingly, the current study examines the prospective link between peer victimization and antisocial behavioral problems in the context of a bidirectional model by including both measures at two time points. Obviously, not all victimized children are antisocial prior to bullying, and victimization experience does not invariably lead to antisocial behavior. Including concurrent and prospective victimization measures of both victimization and antisocial behavior allows us to explore 
how stability or changes in victimization experiences affect later behavioral outcomes over and above the influence of preexisting antisocial behavior.

\section{Family Processes, Peer Victimization, and Antisocial Behavioral Problems}

Studies have reported evidence linking peer victimization to several parenting styles and behaviors, including indifferent-uninvolved parenting (Bowers, Smith, \& Binney, 1994; Duncan, 2004), harsh and inconsistent discipline, physical maltreatment (Shields \& Cicchetti, 2001), and low parental support and warmth (Duncan, 2004) (see Hong \& Espelage, 2012, for a recent review). These findings are generally in line with the attachment theory, which underscores the importance of children's early emotional bonds with parents in the development of subsequent interpersonal relationships (Bowlby, 1988). Children who develop hostile and distrustful relationships with their parents due to low parental warmth and responsiveness may adopt similar patterns of negative expectations when engaging with peers as a result of their greater fear and anxiety. A few studies have directly linked insecure attachment to higher levels of peer bullying and peer victimization (e.g., Smith \& Myron-Wilson, 1998; Troy \& Sroufe, 1987; Waters, Wippman, \& Sroufe, 1979). Cognitive processes and emotional factors, including hostile attributional biases, mistrust, and anger, are considered probable mediators of these links (Bretherton, 1985; Crick \& Dodge, 1994; Kennedy \& Kennedy, 2004).

It is plausible that parenting behaviors not only influence children's exposure to peer victimization, but their responses to peer victimization as well. The present study focuses on the latter issue, examining maternal warmth, mother-child communication, and family conflict as moderators of the link between peer victimization and children's antisocial behavior. The corpus of studies that have assessed the influence of family processes on the strength of the relation between peer victimization and children's adjustment is surprisingly small.

The most rigorous study of this issue, and the only one we are aware of that focuses on externalizing behavior as an outcome, was based on the Environmental Risk Longitudinal Twin sample drawn from a larger birth cohort of twins in England and Wales (Bowes, Maughan, Caspi, Moffitt, \& Arseneault, 2010). All of the twins were same-sex and 56 percent were monozygotic (identical) twin pairs. Children who were bullied when they attended primary school had significantly lower levels of externalizing problems and internalizing problems at ages 10-12 if maternal warmth was high and if the atmosphere in the home was more positive. The buffering effects on externalizing problems were stronger for boys than girls. This study provided especially compelling evidence that maternal warmth had an environmental effect in protecting children from the negative outcomes associated with being bullied. Specifically, the twin who received more maternal warmth within a twin pair had fewer externalizing problems than the twin who received less maternal warmth.

Other investigations of the moderating effect of family processes on the relation between peer victimization and children's adjustment have focused exclusively on internalizing problems as an outcome. Conners-Burrow, Johnson, Whiteside-Mansell, McKelvey, and Gargus (2009) analyzed cross-sectional data from a sample of rural, primarily White, economically diverse fifth- to eleventh-grade students. They found that among bullies, victims of bullying, bully-victims, and children not involved in bullying, those who perceived high levels of parental support, as compared with those who 
perceived low levels of parental support, reported significantly fewer symptoms of anxiety/depression.

Other studies focusing on a diversity of peer-related issues point to protective effects of parental warmth and support. Maternal warmth reduced acting out behavior, anxiety, and learning problems associated with peer rejection in Patterson, Cohn, and Kao's (1989) longitudinal, sociometric study of first graders whereas Baldry and Farrington (2005) found that higher levels of parental support buffered adolescents from peer victimization associated with emotion-oriented coping. In line with these findings is evidence that among fourth-grade girls who experience peer victimization, those who more frequently sought social support from family members or friends to help them cope with victimization experiences had fewer teacher-reported social problems (clinging, not getting along with others) than victimized girls who rarely sought social support (Kochenderfer-Ladd \& Skinner, 2002).

\section{The Current Study}

The current study examines maternal warmth, mother-child communication, and family conflict as moderators of antisocial behaviors associated with peer bullying. Drawing on attachment theory and prior empirical findings, we tested the following hypotheses: (1) Peer victimization (i.e., being a victim of peer bullying) was expected to predict antisocial behavior, both concurrently and longitudinally, over and above the influence of children's prior antisocial behavior. (2) Relationships with mothers were expected to play a moderating role in affecting the predicted outcome. Specifically, higher levels of maternal warmth and higher levels of mother-child communication were expected to attenuate the relation between peer victimization and antisocial behavior. (3) By contrast, greater family conflict was expected to intensify the link between peer victimization and antisocial behavior.

Although prior research indicates gender differences in bullying and externalizing behavioral patterns (e.g., Hanish \& Guerra, 2002; Rusby, Forrester, Biglan, \& Metzler, 2005; Schwartz et al., 1998), there is not enough evidence to confirm that early peer victimization experiences predict later antisocial outcomes equally for boys and girls, over and above the influences of prior antisocial tendencies and stability of victimization status. Findings about gender differences are mixed. Some evidence suggests that boys are more likely than girls to display behavior problems after experiencing peer victimization (e.g., Hanish \& Guerra, 2002; Schwartz et al., 1998). Other studies have reported the opposite findings (Rusby et al., 2005). Still others found little or no gender difference (e.g., Crick \& Bigbee, 1998). The present study assessed whether gender influenced the strength of the direct relation between peer victimization and antisocial behavior, but in light of mixed findings we made no predictions about gender effects. In addition, we made no predictions about whether the hypothesized moderating effects of family processes would vary by child gender, given the paucity of relevant empirical work and the absence of a strong theoretical rationale.

\section{Method}

\section{Participants}

The sample in this study was derived from the Child Development Supplement (CDS) of the Panel Study of Income Dynamics (PSID). Ongoing since 1968, the PSID is a longitudinal survey of a representative sample of US individuals and the families with 


\section{Grace S. Yang and Vonnie C. McLoyd}

whom they reside. Beginning in 1997, information about the developmental outcomes of up to two children ages 0-12 per PSID family was obtained through interviews with the children, their primary caregiver, and other individuals. The current investigation analyzed two waves of CDS data collected in 2002 (labeled Time 1) and 2007 (labeled Time 2). The full sample in 2002 consisted of 2907 children aged 5-19 years. Of the 2907 children from the 2002 sample, 1676 children from the families who remained active in the PSID 2005 panel were still eligible for reinterview in 2007. Data collected in 2007 resulted in completed interviews for 1506 of the 1676 'followable' children in 2007, resulting in a response rate of 90 percent. The reasons for not completing an interview during the 2007 data collection period include no longer residing with a primary caregiver, institutionalization for physical or mental health reasons, being unable to be reached due to changes in contact information, and incarceration.

In our subsample, we only included children who were 8 years old and older in our analysis because only children of at least 8 years of age were asked the child interview questions. We excluded children older than 14 at Time 1 because we wanted to limit our longitudinal analysis to youth under age 19. After restricting the sample by age, our subsample consisted of 1046 children (53 percent boys; 46 percent White, 37 percent Black, 17 percent other ethnicities) aged 8.0-14.1 years $(M=10.65, S D=1.56)$ at Time 1 and aged $12.7-18.8$ years $(M=15.57, S D=1.57)$ at Time 2 .

Within the analytic sample of 1046 children, there was a small amount of missing data among key variables. Item non-response across key variables for our study (e.g., antisocial behavior, peer victimization, and family variables) ranged from .0 percent to 9.1 percent. Missing data were imputed using multiple imputation in STATA 13 (StataCorp, College Station, TX, USA). Due to the excellent response rate from primary caregivers and children participating in the CDS (96 percent and 90 percent, respectively), all individuals were present at both time periods. The present study used data from the children, their primary caregivers, and the interviewers. Because 90.2 percent of primary caregivers were mothers, for convenience primary caregivers are referred to as 'mothers'.

\section{Measures}

Peer Victimization. Victimization by peers at Time 1 was the main independent variable. Our measure included both physical and relational victimization. Using a 6-point scale (ranging from $1=$ not in the past month to $6=$ every day), children reported how often during the preceding month other children in their school or neighborhood had (1) 'picked on me or said means things to me', (2) 'hit me', (3) 'taken my things, like my money or lunch, without asking', and (4) 'purposely left me out of my friends' activities'. In this study, 622 children (68 percent) reported being a target of peer victimization at least once in the preceding month. Peer victimization at Time 2 was measured using the same four-item scale and was included in the current analysis as a control variable. The internal reliability of the measure was acceptable for both years (Cronbach's alpha $=.59$ in 2002, alpha $=.60$ in 2007).

Antisocial Behavior. Antisocial behavior at both Time 1 and Time 2 was measured using items from the behavior problem index (BPI). The BPI gauges the frequency of behavioral problems displayed by children during the previous 3 months (Peterson \& Zill, 1986). Mothers responded to nine items (sample items: My child 'cheats or tells 
lies', 'argues too much', 'bullies or is cruel or mean to others', 'does not seem to feel sorry after misbehaving', 'is impulsive') on a 3-point response scale ('often', 'sometimes', and 'never' true of the child). A total score of antisocial behavior was computed, with higher scores representing more behavior problems. The internal reliability of this measure was acceptable for both years (Cronbach's alpha $=.83$ and .83 , respectively). The child's antisocial behavior at Time 1 was used as a baseline measure, and his or her antisocial behavior at Time 2 was the focal dependent variable.

Maternal Warmth. Maternal warmth was assessed based on interviewers' responses to three questions assessed at Time 1. Based on observations of the mother's behavior and attitude toward the child during the home visit, the interviewer rated the mother on the extent to which she (1) showed warmth when talking with her child, (2) showed pride or pleasure in her child, and (3) was hostile, cold, and harsh to her child. Items were rated on a 5-point scale (the last item was reverse-coded so that higher scores reflect more warmth), and a standardized mean score was used. The internal consistency for this measure was .86 .

Mother-child Communication. The measure of mother-child communication, administered at Time 1, assessed how often the mother and child talked about various topics. Using a 5-point response scale ( $1=$ not in the past month, $5=$ every day), the mother indicated how often she talked with the child about (1) things the child is especially interested in, (2) the child's relationships with friends, (3) current events, like topics going on in the news, and (4) the child's day. A mean score of these four items was used. The internal reliability of this scale was .69 .

Family Conflict. A five-item scale measured the degree of physical and verbal aggression present among family members at Time 1 . The mother indicated how much she agreed or disagreed with each of the following five statements: (1) family members fight a lot, (2) family members often criticize each other, (3) family members sometimes get so angry they throw things, (4) family members sometimes hit each other, and (5) family members always calmly discuss problems ( 1 = completely disagree, 5 = completely agree). The last item was reverse-coded so that higher scores represent higher levels of family conflict. The internal reliability of this measure was .70 .

Control Variables. The child's gender, age, race/ethnicity, family income, and achievement, all assessed at Time 1, were used as control variables because these individual factors have been found to be associated with bullying and antisocial behavior (Cook, Williams, Guerra, Kim, \& Sadek, 2010). Mothers reported the child's gender, age, and race/ethnicity. Family income was operationalized as the ratio of family income to the poverty threshold for the respective household size. Approximately 16 percent of the households in our sample had income below the poverty threshold.

Child achievement was measured using the Woodcock Johnson Psycho-Educational Battery-Revised (WJ-R). The WJ-R test of achievement is a well-established and validated measure that taps several dimensions of children's intellectual ability, including reading and mathematic skills (Esters \& Ittenbach, 1999). In the present study, we created a composite score of achievement based on the letter-word, passage comprehension, and applied problem tests. 


\section{Results}

\section{Analysis Technique}

The hypothesized relations were tested within a structural equation modeling (SEM) framework using a full-information maximum-likelihood (FIML) estimation procedure in STATA. The FIML technique adequately accounted for parameter estimates with incomplete data under the assumption that data were missing at random. Because up to two children from the same family could participate in the study, possible cluster effects may bias the results by deflating standard errors, if not adequately corrected. Thus, all analyses were performed using the cluster option in STATA. This procedure ensured that the standard errors for all parameter estimates were adjusted for potential non-independence. However, goodness-of-fit statistics are not provided in the presence of clustering. Because clustering is more prone to producing biased parameter estimates and less prone to affecting fit statistics, we report the fit statistics without the cluster option and report parameter estimates and significance with the cluster option.

The overall model fit was evaluated using the root mean square error of approximation (RMSEA; Browne, MacCallum, Kim, Andersen, \& Glaser, 2002) in combination with comparative fit index (CFI; Bentler, 1989). The proposed path models were considered a good fit for the data if the CFI value was greater than .95 and the RMSEA was less than .08 (Hu \& Bentler, 1999; McDonald \& Ho, 2002).

\section{Preliminary Analyses}

Table 1 presents bivariate correlations and descriptive statistics of major variables in the hypothesized model. Correlations were in the expected direction, such that children's peer victimization at Time 1 had a significant positive association with antisocial behavior at Time $2(r=.12, p<.01)$. Children's antisocial behavior at Time 1 and Time 2 was negatively associated with mother-child relationship quality (as reflected by maternal warmth and mother-child communication) and positively associated with family conflict. In addition, children's antisocial behavior at Time 1 had a significant positive correlation with their antisocial behavior at Time $2(r=.56)$, and peer victimization at Time 1 had a significant positive correlation with peer victimization at Time $2(r=.23)$. These findings are consistent with previous research documenting substantial stability of aggression and peer experiences over time (e.g., Huesmann, Moise-Titus, Podolski, \& Eron, 2003; Smith, Talamelli, Cowie, Naylor, \& Chauhan, 2004).

The substantive analyses involved three steps. First, we fitted our SEM model examining the association between peer victimization and antisocial behavior to the entire sample. Next, we performed multiple group analyses to test gender as a moderator. To do so, we ran the same model simultaneously for boys and girls. Finally, to test the moderating role of family variables in predicting the growth of antisocial behavior, which is the main focus of our study, we added each interaction term separately to the model, conducting SEM analysis three times for each of the three moderators (maternal warmth, mother-child communication, and family conflict).

The results of the full-sample estimation did not show a significant relationship between Time 1 peer victimization and Time 2 antisocial behavior $(\beta=.026, p=.381)$. As proposed, the next step was to carry the same model into the multiple group analyses to test gender as a moderator. The results of gender differences in the hypothesized path are reported in the next section. 


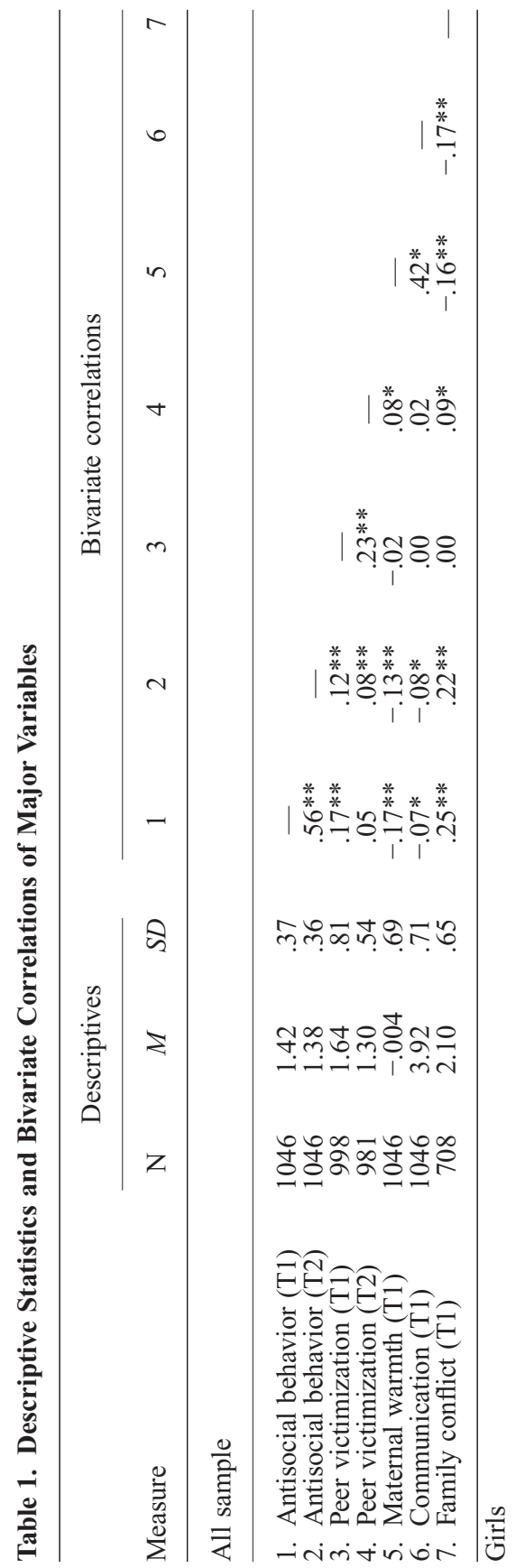

\begin{tabular}{|c|c|c|}
\hline$\stackrel{\stackrel{*}{*}}{\leftrightarrows}$ & & I $\stackrel{*}{\stackrel{*}{*}}$ \\
\hline $\mid \stackrel{*}{*} \stackrel{*}{*} \underset{*}{*}$ & & $\stackrel{*}{\stackrel{*}{*} \stackrel{*}{\sim}}$ \\
\hline | $\stackrel{*}{ \pm} \varrho 0$ & & | ฮำ \\
\hline 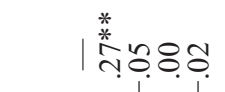 & & 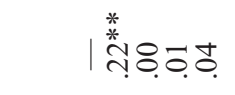 \\
\hline | & & $\mid \stackrel{*}{*} \underset{0}{\infty} \stackrel{*}{*} \underset{*}{*} \stackrel{*}{*} \stackrel{*}{*}$ \\
\hline  & & 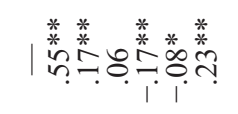 \\
\hline 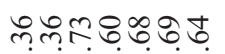 & & 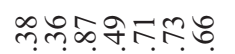 \\
\hline mిm & & 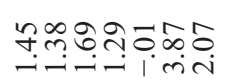 \\
\hline 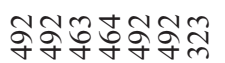 & & 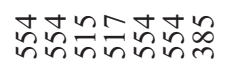 \\
\hline 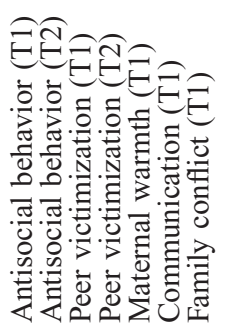 & 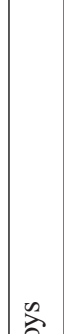 & 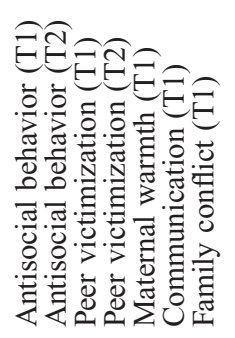 \\
\hline -icistrion & ๑ీ & -icintion \\
\hline
\end{tabular}




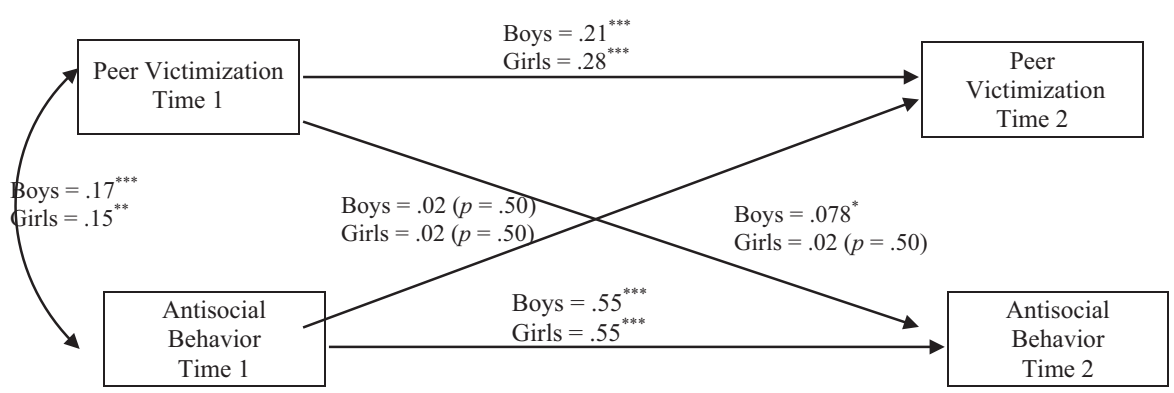

Figure 1. Cross-lagged Path Model Representing the Concurrent and Longitudinal Relations between Peer Victimization at Time 1 and Time 2 and Antisocial Behavior at Time 1 and Time 2.

Notes: Control variables are not shown in the figure, but they were included in the model as exogenous variables. The parameters are standardized path coefficients. ${ }^{*} p<$ $.05, * * p<.01, * * * p<.001$.

\section{Testing Gender Differences in the Relation between Peer Victimization and Antisocial Behavior}

We first created a model that constrained all parameter estimates to be equal across boys and girls, and this model was compared with a model that allowed all parameter estimates to freely vary between both genders. The fully constrained model resulted in a statistically significant deterioration of model fit in comparison to the unconstrained model $\left[\Delta \chi^{2}(39)=192.49, p=.001\right]$, suggesting that the pattern of associations in the model should be assumed to vary between boys and girls.

The path from Time 1 peer victimization to Time 2 peer victimization also significantly differed between boys and girls $\left[\Delta \chi^{2}(1)=5.50, p=.02\right]$. To maximize the parsimony and accuracy of our model, the paths from Time 1 antisocial behavior to Time 2 peer victimization and from Time 1 to Time 2 antisocial behavior were constrained to be equally estimated for boys and girls, because the gender differences for these two paths were not statistically significant $\left[\Delta \chi^{2}(1)=.00, p=.98, \Delta \chi^{2}(1)=\right.$ $2.41, p=.12]$.

Figure 1 presents the model representing the relations between peer victimization experiences and antisocial behavior at Time 1 and Time 2, separately for boys and girls. Because none of the demographic factors, including age, significantly predicted antisocial behavior at Time 2 for either gender, they are not presented in any of the figures. The resulting model fit the data well, with $\chi^{2}(12)=24.91 ; p=.015$; CFI $=.972$; RMSEA $=.045,90$ percent confidence interval (CI) [.019, .071]. We tested whether the specific structural path coefficient from Time 1 peer victimization to Time 2 antisocial behavior differed between boys and girls by comparing the fit of the unconstrained model to the model with a constraint imposed on this specific path. A statistically significant change in chi-square statistics indicates that the effects of peer victimization at Time 1 on antisocial behavior at Time 2 are significantly different for boys and girls $\left[\Delta \chi^{2}(1)=4.00, p=.05\right]$.

The association between peer victimization at Time 1 and antisocial problems at Time 2 was significant only for boys $(\beta=.078, p=.04)$. The significant longitudinal effect was found after controlling for the effect of antisocial behavior at Time 1 and the 
effect of demographic factors on antisocial behavior at Time 2. However, antisocial problems at Time 1 did not significantly predict peer victimization at Time 2 for either gender $(\beta=.02, p=.50)$. This non-significant path coefficient suggests the temporal ordering of the relation between peer victimization and antisocial behavior. That is, independent of the effects due to boys' baseline measure of antisocial problems or to the boys' age, race, achievement level, or family income, boys' peer victimization at Time 1 predicted a small but statistically significant increase in antisocial behavioral problems at Time 2 .

Because of the wide age range in this sample, we tested whether age moderated the link between peer victimization and antisocial behavior. The likelihood ratio test revealed no statistical significance between different age groups $\left[\Delta \chi^{2}(1)=.21\right.$, $p=.65]$. Also, the three-way interaction among age, gender, and peer victimization was not significant $\left[\Delta \chi^{2}(6)=7.54, p=.27\right]$.

\section{Testing the Moderating Effects of Family Processes and Gender}

Using this model as a baseline, we examined the moderating role of parenting practices and family conflict in predicting the growth of antisocial behavior. To test the statistical significance of the potential moderators on the hypothesized paths, we included an interaction product term for each parenting factor (i.e., maternal warmth $\times$ victimization, mother-child communication $\times$ victimization, and family conflict $\times$ victimization) in the model as an observed variable. For ease of interpretation and to avoid multicollinearity issues, we centered all predictor variables before calculating the statistical interaction term. In each of the three SEM models, the moderating effect was tested by a two-group analysis using gender as a grouping variable.

Maternal Warmth. The SEM model (see Figure 2) testing the maternal warmth by peer victimization interaction was based on a sample of 1046 children (554 boys; 492 girls). The model exhibited an excellent fit with the data, $\chi^{2}(19)=38.91 ; p=.01 ; \mathrm{CFI}=.958$; RMSEA $=.045,90$ percent CI $[.024, .065]$. There was a significant interaction effect between maternal warmth and peer victimization on antisocial behavior, but only for girls $(\beta=-.42, p=.041 ; \beta=-.10, p=.58$ for girls and boys, respectively). A chi-square difference test revealed that the magnitude of this longitudinal association significantly differed between boys and girls [ $\Delta \chi^{2}$ (1) $\left.4.07, p=.043\right]$.

For girls, the association between peer victimization at Time 1 and antisocial behavior at Time 2 depended on the level of maternal warmth at Time 1, with higher warmth attenuating the link between peer victimization and antisocial behavior. Maternal warmth at Time 1 had a significant negative correlation with antisocial tendencies at Time 1 ( $r=-.22, p<.000 ; r=-.12, p=.001$, for boys and girls, respectively). However, maternal warmth at Time 1 was unrelated to antisocial behavior at Time 2 ( $\beta=-.024, p>.05$, for both boys and girls). According to the Bentler-Raykov squared multiple correlation coefficients, the predictors in the model accounted for 31.38 percent of the variance in boys' antisocial behavior at Time 2 and 35.29 percent of the variance in girls' antisocial behavior at Time 2.

Mother-child Communication. As Figure 3 shows, the model testing the interaction between mother-child communication and peer victimization also exhibited an excellent fit with the data, $\chi^{2}(14)=27.75 ; p=.05 ; \mathrm{CFI}=.977$; RMSEA $=.035,90$ percent CI $[.003, .057]$. As with maternal warmth, there was a significant interaction effect of 


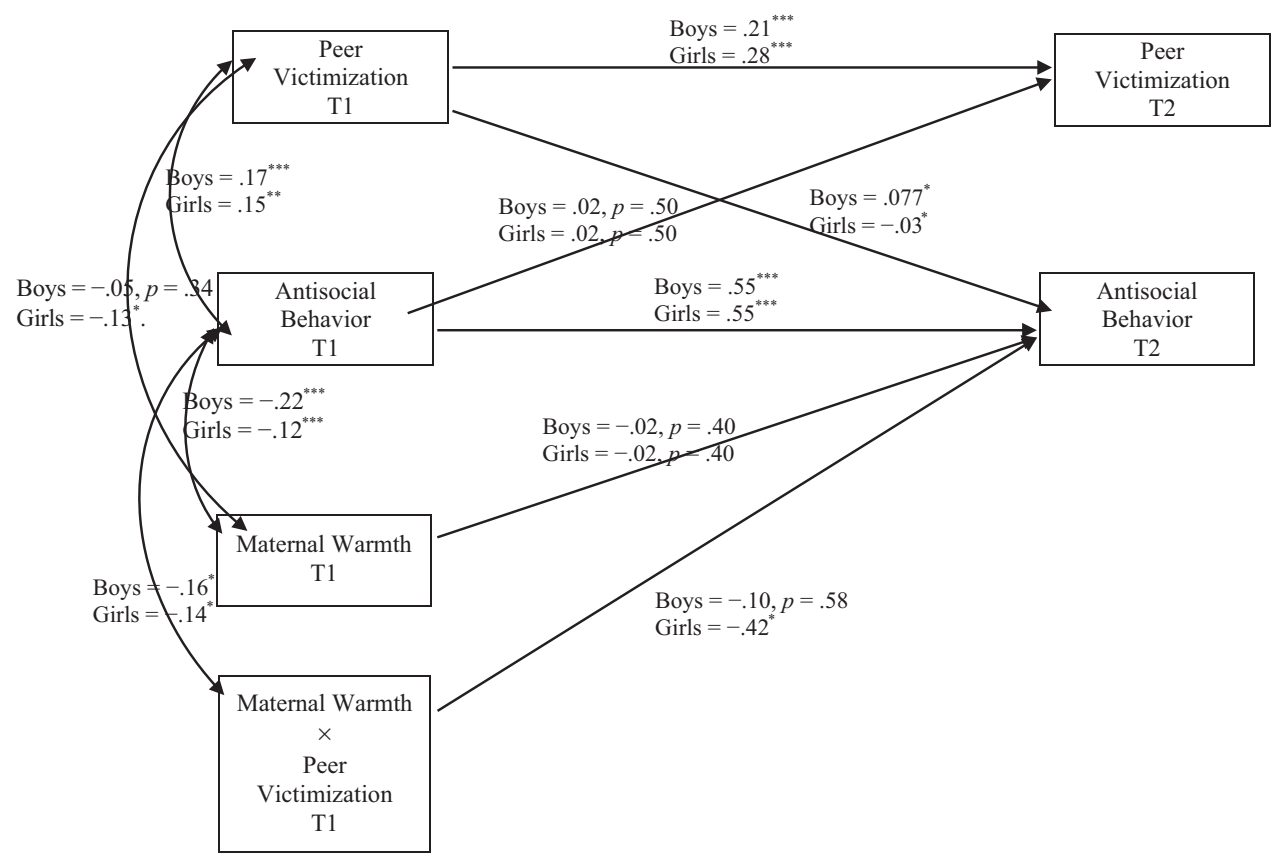

Figure 2. Moderating Effect of Maternal Warmth on the Concurrent and Longitudinal Relations between Bully Victimization at Time 1 and Time 2 and Antisocial Behavior at Time 1 and Time 2.

Notes: Control variables are not shown in the figure, but they were included in the model as exogenous variables. The parameters are standardized path coefficients. $* p<.05, * * p<.01, * * * p<.001$.

mother-child communication for girls but not for boys [ $\left.\Delta \chi^{2}(1) 4.37, p=.037\right]$. For girls, the association between peer victimization at Time 1 and antisocial behavior at Time 2 was significantly reduced as the level of mother-child communication increased $(\beta=-.10, p=.02)$. For boys, the longitudinal association between peer victimization and antisocial behavior was not contingent upon different levels of mother-child communication $(\beta=.01, p=.871)$.

For both boys and girls, mother-child communication at Time 1 was negatively associated with antisocial tendencies at Time 2 , but the magnitude of these relations was very small and only approached statistical significance $(\beta=-.02, p=.08 ; \beta=-.02$, $p=.08$, for boys and girls, respectively). The predictors in the model accounted for 37.2 percent and 37.0 percent of the variance in antisocial behavior at Time 2 for boys and girls, respectively.

Family Conflict. As Figure 4 shows, the model testing the family conflict by peer victimization interaction also fit the data well, $\chi^{2}(14)=36.98 ; p=.003$; CFI $=.958$; RMSEA $=.047,90$ percent CI $[.026, .068]$. As with maternal warmth and motherchild communication, the interaction effect between family conflict and peer victimization was significant for girls, but not for boys. This interaction effect was marginally significant $\left[\Delta \chi^{2}\right.$ (1) 2.93, $\left.p=.08\right]$. Among girls, the association between peer victimization at Time 1 and antisocial outcome at Time 2 was significantly amplified as the 


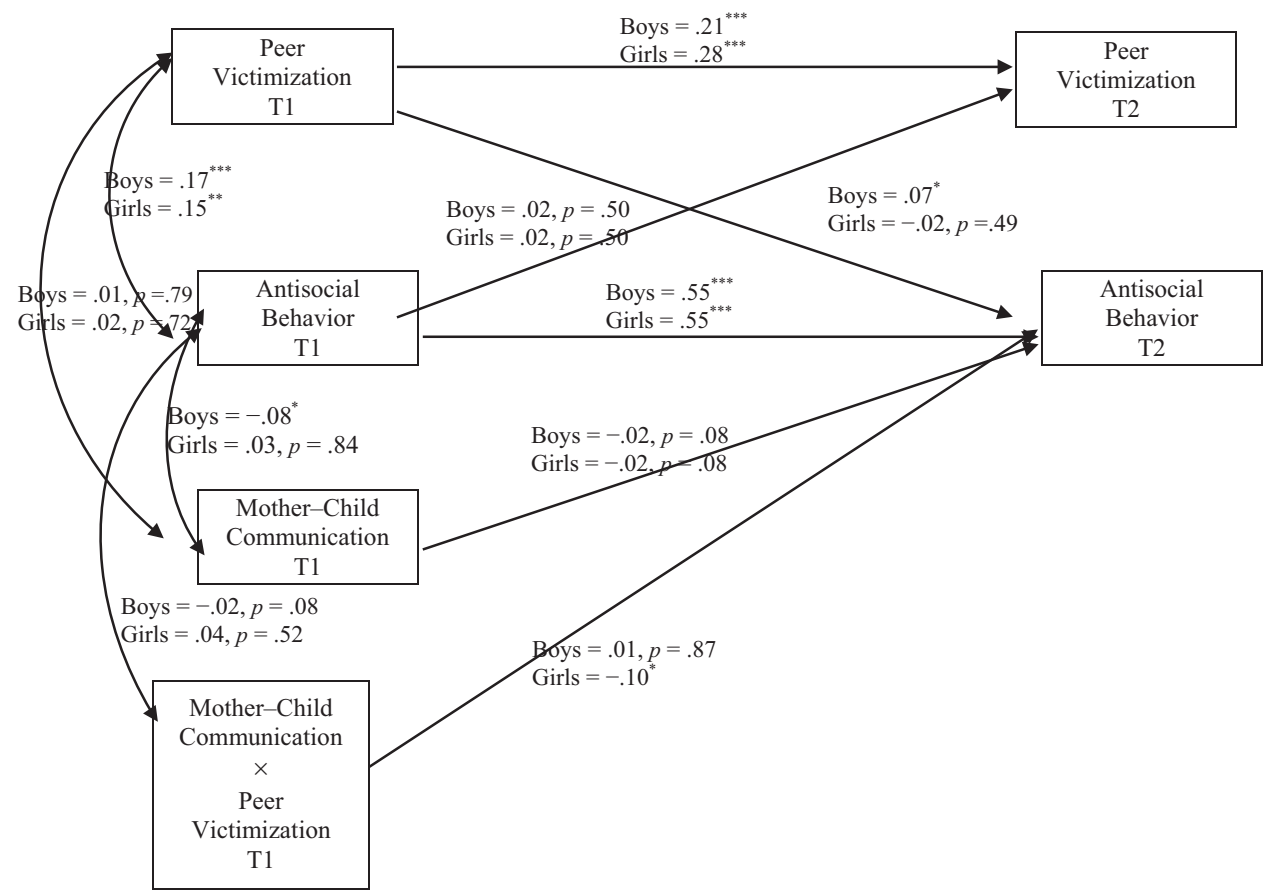

Figure 3. Moderating Effect of Mother-child Communication on the Concurrent and Longitudinal Relations between Peer Victimization at Time 1 and Time 2 and Antisocial Behavior at Time 1 and Time 2.

Notes: Control variables are not shown in the figure, but they were included in the model as exogenous variables. The parameters are standardized path coefficients. $* p<.05, * * p<.01, * * * p<.001$.

level of family conflict increased $(\beta=.11, p=.03)$. For boys, the longitudinal relation between peer victimization and antisocial behavior was unrelated to different levels of family conflict.

Family conflict at Time 1 was positively correlated with antisocial behavior at Time $1(\beta=.11, p=.03$ for boys and girls) and antisocial tendencies at Time $2(r=.24, p<$ $.001 ; r=.29, p<.001$, for boys and girls, respectively). The predictors in the model accounted for 37.43 percent and 37.50 percent of the variance in antisocial behavior at Time 2 for boys and girls, respectively.

\section{Discussion}

The present study adds to our sparse knowledge about the role of family and parenting factors in mitigating and amplifying the impact of peer victimization on antisocial behavior. The findings partially supported our hypotheses, with child gender emerging as variable of major significance in the hypothesized relationships. Both the direct association between peer victimization and antisocial behavior and the hypothesized moderating influences varied as a function of child gender. The findings for boys, but not girls, supported our hypothesis about the longitudinal relation between peer victimization and antisocial behavior. Boys who experienced peer victimization more 


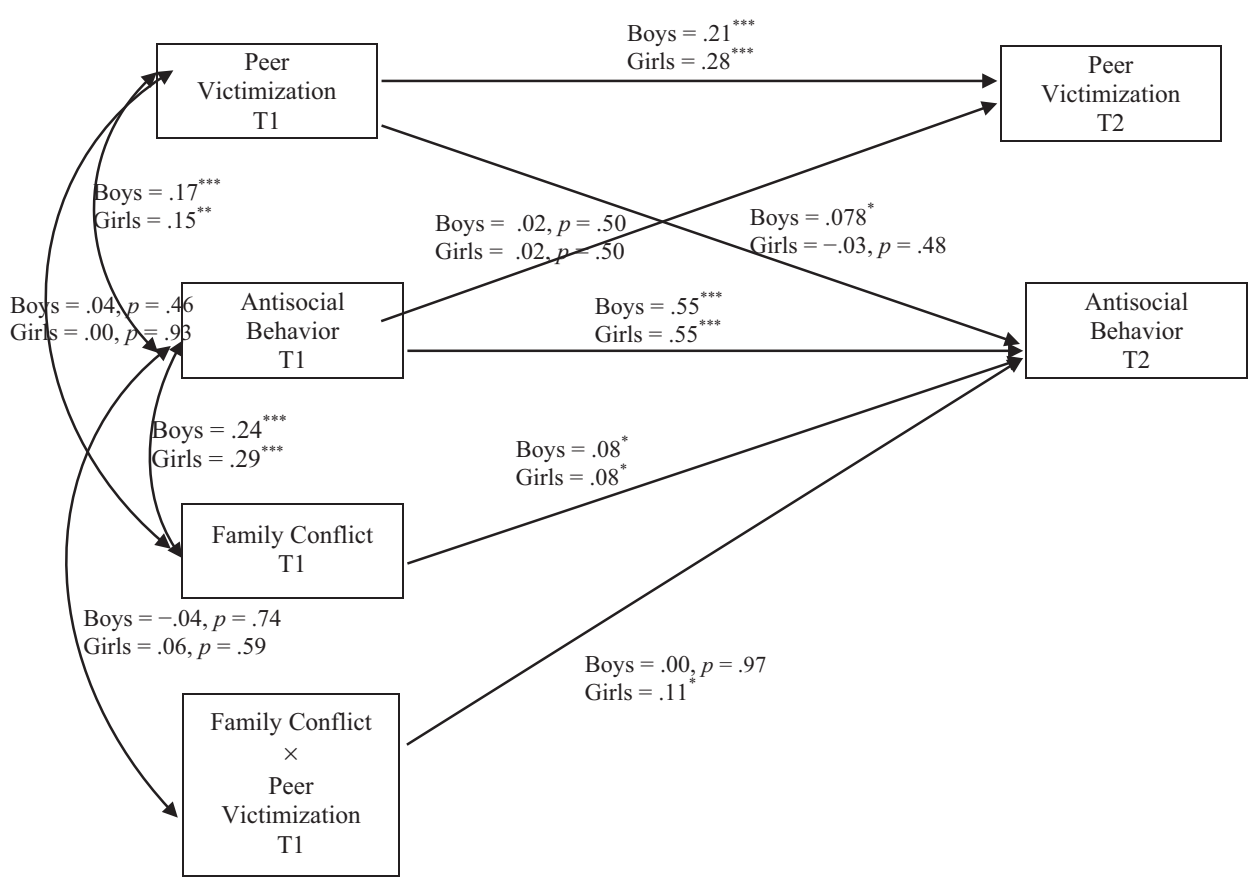

Figure 4. Moderating Effect of Family Conflict on the Concurrent and Longitudinal Relations between Peer Victimization at Time 1 and Time 2 and Antisocial Behavior at Time 1 and Time 2.

Notes: Control variables are not shown in the figure, but they were included in the model as exogenous variables. The parameters are standardized path coefficients. $* p<.05, * * p<.01, * * * p<.001$.

frequently displayed higher levels of antisocial behavior 5 years later, over and above concurrent experiences of peer victimization, the influence of prior antisocial behavior, and the effects of demographic factors. This longitudinal relation was not contingent upon or moderated by parenting or family factors whereas, for girls, antisocial outcomes depended on variation in maternal warmth, mother-child communication, and family conflict in a manner consistent with our predictions. Specifically, when girls experienced higher levels of warmth and more frequent communication with their mothers, the link between peer victimization and antisocial behavior was attenuated whereas when they experienced higher levels of family conflict the link was amplified. In short, both positive and negative aspects of family interaction influenced girls' but not boys' response to peer victimization.

A number of factors may underlie this pattern of gender difference in moderating influences. There was a significant gender difference in the scores for mother-child communication and family conflict, $[t(1044)=2.59, p=.010$ and $t(706)=1.97, p=$ .049 , respectively], with girls having higher scores than boys. Such a gender difference is perhaps making these parenting/family variables more salient, and hence more influential for girls than for boys. However, this explanation is challenged by the fact that maternal warmth, like mother-child communication and family conflict, moderated the link between peer victimization and antisocial behavior in girls, but not in 
boys, even though no gender difference existed in the mean level of observed maternal warmth $[t(904)=1.06, p=.291]$.

It is plausible that the gender differences in moderating influences are due to differences in peer context and where children spend their time. In their response to peer victimization, boys may be less susceptible than girls to the influence of the family environment because they tend to spend less time at home compared with girls (Kroneman, Loeber, \& Hipwell, 2004). The sway of the family environment may be diminished further by the tendency of boys to have larger friendship and peer networks than girls, although this difference is not always found (Goodwin, 2002; Rubin, Bukowski, \& Parker, 2007). If boys have larger friendship and peer networks than girls, peers may assume greater salience and influence in their emotional lives, with the potential consequence that boys' response to peer victimization, relative to girls' response, may depend less on family interaction patterns and more on their interactions with peers. The findings of Simpkins and Parke's (2001) study of relations between parents' and children's friendships suggest that boys' social lives indeed may be less impacted by their families than the social lives of girls. Different qualities of paternal and maternal friendships were related to daughters' friendship qualities whereas boys' friendship patterns were largely unrelated to either the mothers' or the fathers' friendship qualities.

It is also likely that our measure of mother-child communication reflects a transactional process driven in part by children's initiation of communication with their mothers. In the present study, mothers reported communicating with their sons less frequently than their daughters. This difference probably reflects a lesser tendency for sons, compared with daughters, to initiate discussions with their mothers. A reasonable extrapolation of this difference is that boys, compared with girls, talk less with their mothers about peer victimization experiences, and consequently receive less support and intervention on their behalf to lessen the occurrence and mitigate the negative effects of peer victimization. The potential for mother-son communication to protect boys from the negative effects of peer victimization may be further eroded if boys are less inclined than girls to embrace and implement the suggestions that they receive from their mothers about how to cope with peer victimization. Prior research indicates that boys are less likely than girls to view support as the best strategy for ending peer victimization or helping them feel better (Hunter, Boyle, \& Warden, 2004), and less willing than girls to seek help from adults, including their parents, in dealing with bullying generally (Glover, Gough, Johnson, \& Cartwright, 2000; Hunter et al., 2004; Smith et al., 2004).

Our finding that mother-son communication was less frequent and less protective than mother-daughter communication is reminiscent of findings from Ceballo, Dahl, Aretakis, and Ramirez's (2001) study of the influence of mothers' knowledge about their children's encounters with violence. Mother-daughter agreement (mothers and children independently reported whether the child was exposed to different types of community violence, including personal victimization and witnessing violence) was significantly higher than mother-son agreement, suggesting that mothers were more knowledgeable about their daughters' exposure to violence than their sons' exposure. Moreover, higher levels of mother-child concordance regarding children's victimization experiences were significantly associated with fewer post-traumatic stress disorder (PTSD) symptoms, a finding that suggests that children may benefit psychologically from increased opportunities to talk with parents about their experiences with violence, including bullying and other forms of peer victimization. 


\section{Grace S. Yang and Vonnie C. McLoyd}

The age range of children in the present study is quite wide (8-14 years at Time 1). Although child age was negatively associated with peer victimization at Time $1(r=$ $-.18 p<.01)$ and Time $2(r=-.17, p<.01)$, it was unrelated to antisocial behavior at Time $1(r=.02, \mathrm{NS})$ and Time $2(r=.002$, NS), and did not moderate the link between peer victimization and antisocial behavior. Notwithstanding the latter finding, further examination is warranted of whether the role of the family in the relation of peer victimization to later antisocial behavior differs as a function of developmental period (e.g., early childhood, middle childhood, adolescence), given the existence of marked variations across developmental periods in how much time children spend with peers and parents, and in the salience and the psychological importance of peers and friends (Eccles, 1999).

Among the strengths of this study are an economically and ethnically diverse sample of families, the expansion of family interaction variables beyond those examined in prior studies, the measurement of key variables based on information from different informants, a cross-lagged longitudinal design, and strong statistical controls that resulted in a conservative test of moderating influences. However, there are several limitations in the study that need to be considered. Our findings suggest that peer victimization contributes to, but is not a consequence of, antisocial behavior. However, Reijntjes et al.'s (2011) meta-analysis of 14 longitudinal studies found a symmetrical bidirectional relationship between peer victimization and externalizing problems. Because our findings are based on a single study with only two time points, they must be interpreted with caution in light of the findings from Reijntjes et al.'s meta-analysis.

Because some of our measures (e.g., mother-child communication, antisocial behavior) are based on mothers' reports, the findings may be subject to socially desirable responding and non-random measurement errors. Although some past studies have used parent reports as the only source of information about parent-child relations and children's behavioral adjustment (e.g., Achenbach, McConaughy, \& Howell, 1987), reports from multiple respondents will provide more valid and unbiased information.

Another limitation is our exclusive focus on mothers' interactions with their children and lack of attention to fathers' and siblings' influences. Family systems theory emphasizes the importance of patterns of interaction within and across family subsystems (e.g., marital and parent-child, parent-child and sibling). It proposes that individual family members are embedded in the larger family system and cannot be fully understood independent of the context of that system and the behavior of other family members (Cox \& Paley, 1997). In relation to the present study, the warmth that fathers displayed toward their sons, and the frequency of father-son communication, may have been more consequential than maternal warmth and mother-child communication as protective factors for boys who experienced peer victimization. In addition, boys generally may be more disposed to talking with their fathers than their mothers about experiences of peer victimization, potentially amplifying the protective role of fathers in the emotional lives of sons. We were unable to address these issues because the requisite data were not in the CDS dataset. Future research that integrates a focus on father-child relations and sibling relations will complement extant knowledge and significantly advance our understanding of the role of family processes in mitigating the negative effects of peer victimization.

In addition, it is important to point out that the gender differences in moderating influences found in the present study are at odds with the findings from Bowes et al. (2010), who found that the buffering effects of maternal warmth and a positive home 
atmosphere on delinquency and aggression were stronger for boys than girls. The conflicting findings may derive partly from differences in the study samples. The present study is based on an economically and racially diverse and nationally representative sample of American children. By contrast, Bowes et al.'s investigation focused on a highly unique sample consisting of same-sex twins, a disproportionate number of whom grew up in adverse environments in England and Wales. Future studies that help resolve this discrepancy in findings would be highly valuable. More generally, the societal costs of antisocial behavior and heightened concern about peer victimization justify considerably more study of family processes that affect children's response to peer victimization.

\section{References}

Achenbach, T. M., McConaughy, S. H., \& Howell, C. T. (1987). Child/adolescent behavioral and emotional problems: Implications of cross-informant correlations for situational specificity. Psychological Bulletin, 101, 213-232. doi: 10.1037/0033-2909.101.2.213

Anderson, C. A., \& Huesmann, L. R. (2003). Human aggression: A social-cognitive view. In M. A. Hogg, \& J. Cooper (Eds.), Handbook of social psychology (pp. 296-323). London: Sage.

Baldry, A. C., \& Farrington, D. P. (2005). Protective factors as moderators of risk factors in adolescence bullying. Social Psychology of Education: An International Journal, 8, 263-284. doi: 10.1007/s11218-005-5866-5

Bandura, A. (1986). Social foundations of thought and action: A social cognitive theory. Englewood Cliffs, NJ: Prentice Hall.

Bandura, A. (2002). Social cognitive theory in cultural context. Applied Psychology, 51, 269 290. doi: 10.1111/1464-0597.00092

Bentler, P. M. (1989). EQS, structural equations, program manual. Program Version 3.0. Los Angeles, CA: BMDP Statistical Software, Inc.

Bowers, L., Smith, P. K., \& Binney, V. (1994). Perceived family relationships of bullies, victims and bully/victims in middle childhood. Journal of Social and Personal Relationships, 11, 215-232. doi: 10.1177/0265407594112004

Bowes, L., Maughan, B., Caspi, A., Moffitt, T. E., \& Arseneault, L. (2010). Families promote emotional and behavioural resilience to bullying: Evidence of an environmental effect. Journal of Child Psychology and Psychiatry, 51, 809-817. doi: 10.1111/j.14697610.2010.02216.x

Bowlby, J. (1988). A secure base: Parent-child attachment and healthy human development. New York: Basic Books.

Bretherton, I. (1985). Attachment theory: Retrospect and prospect. Monographs of the Society for Research in Child Development, 209, 3-35. doi: 10.2307/3333824

Bronfenbrenner, U. (1986). Ecology of the family as a context for human development: Research perspectives. Developmental Psychology, 22, 723-742. doi: 10.1037/00121649.22.6.723

Browne, M. W., MacCallum, R. C., Kim, C., Andersen, B. L., \& Glaser, R. (2002). When fit indices and residuals are incomplete. Psychological Methods, 7, 403-421. doi: 10.1037/1082989X.7.4.403

Ceballo, R., Dahl, T., Aretakis, M., \& Ramirez, C. (2001). Inner-city children's exposure to community violence: How much do parents know? Journal of Marriage and the Family, 63, 927-940.

Conners-Burrow, N. A., Johnson, D. L., Whiteside-Mansell, L., McKelvey, L., \& Gargus, R. A. (2009). Adults matter: Protecting children from the negative impacts of bullying. Psychology in the Schools, 46, 593-604. doi: 10.1002/pits.20400

Cook, C. R., Williams, K. R., Guerra, N. G., Kim, T. E., \& Sadek, S. (2010). Predictors of bullying and victimization in childhood and adolescence: A meta-analytic investigation. School Psychology Quarterly: The Official Journal of the Division of School Psychology, American Psychological Association, 25, 65-83. doi: 10.1037/a0020149

Cox, M. J., \& Paley, B. (1997). Families as systems. Annual Review of Psychology, 48, 243-267. 


\section{Grace S. Yang and Vonnie C. McLoyd}

Crick, N. R., \& Bigbee, M. A. (1998). Relational and overt forms of peer victimization: A multiinformant approach. Journal of Consulting and Clinical Psychology, 66, 337-347. doi: 10.1037/0022-006X.66.2.337

Crick, N. R., \& Dodge, K. A. (1994). A review and reformulation of social informationprocessing mechanisms in children's social adjustment. Psychological Bulletin, 115, 74-101. doi: 10.1037/0033-2909.115.1.74

Dodge, K. A., Lochman, J. E., Harnish, J. D., Bates, J. E., \& Pettit, G. S. (1997). Reactive and proactive aggression in school children and psychiatrically impaired chronically assaultive youth. Journal of Abnormal Psychology, 106, 37-51.

Duncan, R. D. (2004). The impact of family relationships on school bullies and victims. In Dorothy Lynn Espelage, Susan M. Swearer. (Eds.), Bullying in American schools: A socialecological perspective on prevention and intervention (pp. 227-244). Mahwah, NJ: Lawrence Erlbaum Associates.

Eccles, J. (1999). The development of children ages 6 to 14. The Future of Children/Center for the Future of Children, the David and Lucile Packard Foundation, 9, 30-44.

Esters, I. G., \& Ittenbach, R. F. (1999). Contemporary theories and assessments of intelligence: A primer. Professional School Counseling, 2, 373-376.

Glover, D., Gough, G., Johnson, M., \& Cartwright, N. (2000). Bullying in 25 secondary schools: Incidence, impact and intervention. Educational Research, 42, 141-156.

Goodwin, M. H. (2002). Exclusion in girls' peer groups: Ethnographic analysis of language practices on the playground. Human Development, 45, 392-415.

Hanish, L. D., \& Guerra, N. G. (2002). A longitudinal analysis of patterns of adjustment following peer victimization. Development and Psychopathology, 14, 69-89. doi: 10.1017/ S0954579402001049

Hodges, E. V., Boivin, M., Vitaro, F., \& Bukowski, W. M. (1999). The power of friendship: Protection against an escalating cycle of peer victimization. Developmental Psychology, 35, 94-101. doi: 10.1037/0012-1649.35.1.94

Hong, J. S., \& Espelage, D. L. (2012). A review of research on bullying and peer victimization in school: An ecological system analysis. Aggression and Violent Behavior, 17, 311-322. doi: 10.1016/j.avb.2012.03.003

Hu, L. T., \& Bentler, P. M. (1999). Cutoff criteria for fit indexes in covariance structure analysis: Conventional criteria versus new alternatives. Structural Equation Modeling: A Multidisciplinary Journal, 6, 1-55. doi: 10.1080/10705519909540118

Huesmann, L. R., \& Kirwil, L. (2007). Why observing violence increases the risk of violent behavior by the observer. In D. J. Flannery, A. T. Vazsonyi, \& I. D. Waldman (Eds.), The Cambridge handbook of violent behavior and aggression (pp. 545-570). Cambridge, UK: Cambridge University Press. doi: 10.1017/CBO9780511816840.029

Huesmann, L. R., Moise-Titus, J., Podolski, C. L., \& Eron, L. D. (2003). Longitudinal relations between children's exposure to TV violence and their aggressive and violent behavior in young adulthood: 1977-1992. Developmental Psychology, 39, 201-221. doi: 10.1037/00121649.39.2.201

Hunter, S., Boyle, J., \& Warden, D. (2004). Help seeking amongst child and adolescent victims of peer-aggression and bullying: The influence of school-stage, gender, victimization, appraisal, and emotion. The British Journal of Educational Psychology, 74, 375-390.

Kennedy, J. H., \& Kennedy, C. E. (2004). Attachment theory: Implications for school psychology. Psychology in the Schools, 41, 247-259. doi: 10.1002/pits.10153

Kochenderfer-Ladd, B., \& Skinner, K. (2002). Children's coping strategies: Moderators of the effects of peer victimization? Developmental Psychology, 38, 267-278. doi: 10.1037/00121649.38.2.267

Kroneman, L., Loeber, R., \& Hipwell, A. E. (2004). Is neighborhood context differently related to externalizing problems and delinquency for girls compared with boys? Clinical Child and Family Psychology Review, 7, 109-122.

Lynch, M., \& Cicchetti, D. (2002). Links between community violence and the family system: Evidence from children's feelings of relatedness and perceptions of parent behavior. Family Process, 41, 519-532. doi: 10.1111/j.1545-5300.2002.41314.x

McDonald, R. P., \& Ho, M. H. R. (2002). Principles and practice in reporting structural equation analyses. Psychological Methods, 7, 64-82. doi: 10.1037/1082-989X.7.1.64 
Morrow, M. T., Hubbard, J. A., Rubin, R. M., \& McAuliffe, M. D. (2008). The relation between childhood aggression and depressive symptoms. Merrill-Palmer Quarterly, 54, 316-340.

Orue, I., Bushman, B. J., Calvete, E., Thomaes, S., de Castro, B. O., \& Hutteman, R. (2011). Monkey see, monkey do, monkey hurt: Longitudinal effects of exposure to violence on children's aggressive behavior. Social Psychological and Personality Science, 2, 432-437. doi: $10.1177 / 1948550610396586$

Ostrov, J. M. (2010). Prospective associations between peer victimization and aggression. Child Development, 81, 1670-1677.

Patterson, C. J., Cohn, D. A., \& Kao, B. T. (1989). Maternal warmth as a protective factor against risks associated with peer rejection among children. Development and Psychopathology, 1, 21-38. doi: 10.1017/s0954579400000225

Peterson, J. L., \& Zill, N. (1986). Marital disruption, parent-child relationships, and behavioral problems in children. Journal of Marriage and the Family, 48, 295-307.

Reijntjes, A., Kamphuis, J. H., Prinzie, P., Boelen, P. A., Van der Schoot, M., \& Telch, M. J. (2011). Prospective linkages between peer victimization and externalizing problems in children: A meta-analysis. Aggressive Behavior, 37, 215-222. doi: 10.1002/ab.20374

Rubin, K. H., Bukowski, W. M., \& Parker, J. G. (2007). Peer interactions, relationships, and groups. In Nancy Eisenberg, Arizona State University (Ed.), Handbook of child psychology (6th ed., vol. 3, pp. 571-645). New York: Wiley. doi: 10.1002/9780470147658.chpsy0310

Rusby, J. C., Forrester, K. K., Biglan, A., \& Metzler, C. W. (2005). Relationships between peer harassment and adolescent problem behaviors. The Journal of Early Adolescence, 25, 453477. doi: $10.1177 / 0272431605279837$

Salmivalli, C., \& Helteenvuori, T. (2007). Reactive, but not proactive aggression predicts victimization among boys. Aggressive Behavior, 33, 198-206.

Schwartz, D., McFadyen-Ketchum, S. A., Dodge, K. A., Pettit, G. S., \& Bates, J. E. (1998). Peer group victimization as a predictor of children's behavior problems at home and in school. Development and Psychopathology, 10, 87-99.

Shields, A., \& Cicchetti, D. (2001). Parental maltreatment and emotion dysregulation as risk factors for bullying and victimization in middle childhood. Journal of Clinical Child and Adolescent Psychology: The Official Journal for the Society of Clinical Child and Adolescent Psychology, American Psychological Association, Division 53, 30, 349-363. doi: 10.1207/ s15374424jccp3003_7

Simpkins, S. D., \& Parke, R. D. (2001). The relations between parental friendships and children's friendships: Self-report and observational analysis. Child Development, 72, 569-582. doi: 10.1111/1467-8624.00297

Smith, P. K., \& Myron-Wilson, R. (1998). Parenting and school bullying. Clinical Child Psychology and Psychiatry, 3, 405-417. doi: 10.1177/1359104598033006

Smith, P. K., Talamelli, L., Cowie, H., Naylor, P., \& Chauhan, P. (2004). Profiles of non-victims, escaped victims, continuing victims and new victims of school bullying. The British Journal of Educational Psychology, 74, 565-581. doi: 10.1348/0007099042376427

Troy, M., \& Sroufe, L. A. (1987). Victimization among preschoolers: Role of attachment relationship history. Journal of the American Academy of Child and Adolescent Psychiatry, 26, 166-172. doi: 10.1097/00004583-198703000-00007

Waters, E., Wippman, J., \& Sroufe, L. A. (1979). Attachment, positive affect, and competence in the peer group: Two studies in construct validation. Child Development, 50, 821-829. doi: $10.2307 / 1128949$ 